\title{
CLIMATE CHANGE AND AGRICULTURE: A NEPALESE CASE
}

\author{
Mandip Rai, MSc., Agri. Dev. Eco. ${ }^{13}$
}

\begin{abstract}
Despite having slight disagreements on the magnitude, timing and spatial distribution of climate change, scientists agree that the recent climate change has been much faster than in the past. This has been partly to the natural phenomenon but mostly because of human activities. There is also an agreement that the poorer nations will suffer more as a consequence of the climate change than the developed nations. In this connection, the Nepalese agriculture does not seem to gain but rather lose during the process of global climate change. Even so, serious preparedness and actions can be taken that can hopefully impede the process of climate change and slowly but surely adapt to the rapidly changing climate. To achieve that, agriculture's role as a driving force for climate change can be condensed by taking measures that reduce the rate and volume of Greenhouse Gas emissions from agriculture on the one hand, and developing diverse and resilient plant and animals breeds, on the other, that are capable of yielding as much as the current levels or even better under the foreseen changed climatic conditions.
\end{abstract}

\section{Background}

The increasing pace of climate change and its effects on human lives has been a very important issue of discussion and debate in recent years. Even though the degree of climate change and its temporal and spatial impacts are open to debate, a general consensus exists that the poorer countries will suffer more in an irony to their smaller roles in bringing about the current faster pace of climate change. The Independent (UK, 9 May 2007) actually claims that the existing divisions between rich and poor countries will even be exacerbated by the pattern of climate-change impacts in the coming years. Since it has been realised that the human activities, especially of the more developed nations, have contributed greatly to the climate change, a positive change in those activities may somewhat retard the process though the climate change in the future is bound to be a lot faster than in the present or the past. This paper, therefore, aims at giving a succinct overview of climate change and its origins in simple and comprehensible terms. Thereafter, it assesses impacts of climate change on Nepalese geology and hence on Nepalese agriculture, reviews the relevant existing policies and provides options to tackle the associated problems. Due to the magnitude of such a grave topic, generation and analysis of primary data has not been attempted but an extensive literature review has been conducted to inform a larger audience in a lucid style.

\section{Climate Change and Its Consequences}

The earth's atmosphere acts much like a greenhouse. The Greenhouse Gases, containing mostly water vapour, carbon dioxide $\left(\mathrm{CO}_{2}\right)$, methane $\left(\mathrm{CH}_{4}\right)$, halocarbons, and nitrous oxide $\left(\mathrm{N}_{2} \mathrm{O}\right)$, trap some of the energy received from the sun and thus act as a thermostat controlling the earth's climate. Without this natural greenhouse effect, the average temperature on earth would not be the current $+15^{\circ}$ Celsius but would be $-18^{\circ} \mathrm{C}$, making life impossible. Even though it has been scientifically accepted that the earth's climate has always been constantly changing with a steady rise in average global temperature, modern lifestyles, gas emissions from vehicles and industries, burning of fossil fuels and the destruction of forests (natural

${ }^{13}$ Planning Officer, CLDP, DOLS, Harihar Bhawan. Email : mandeeprai @ gmail.com 
removals of The Greenhouse Gases have raised the levels of existing The Greenhouse Gases to alarming levels and rates, thus making the current rate of the climate change much more rapid than any time in the last 10,000 years. Global temperature has increased by 0.3 to $0.6^{\circ} \mathrm{C}$ over the past century with most of the rise occurring in the last 40 years. If no action at a global level is taken to curb this trend, then scientists predict that the average global temperature will increase by 1.4 to $5.8^{\circ} \mathrm{C}$ over the next hundred years, which may lead to consequences more drastic than all the natural calamites that have been documented over the last 100,000 years (NRCS, 1995).

Intergovernmental Panel on Climate Change (IPCC) predicts that though Canada, northern Europe and some parts of the Soviet Union may benefit by the increased cereal productivity due to the climate change, sub-Sahara Africa, southern Europe and southern Asia could see widespread declines in the cropland productivity. IPCC further goes on to state that even though the regional, sub-regional and national impacts, magnitude and the rate of change is subject to discussion, it is generally accepted that: (a) the increase in the earth's overall temperature will alter precipitation patterns, trigger extreme weather conditions and may raise the sea level and threaten fresh water sources, (b) change delicate ecosystems, such as mountain flora and fauna, (c) disrupt farming, fishing, forestry and (d) directly or indirectly affect human health and endanger animal habitat.

\section{Agriculture and Climate Change}

Since activities related to agriculture also release the Greenhouse Gases agriculture could add to the trend of rising temperature. However, agriculture also plays an appreciative role of making positive contribution to climate change (IISD \& IES, March 1997). Improved land management practices could act as natural Greenhouse Gases sinks. With a hotter climate agriculture can either enjoy opportunities or face risks. Longer growing seasons and warmer temperatures may create opportunities for diversifications and for the cultivation of new crops. And still warmer climate may mean more extreme weather, pests and erosion risks. Adapting to the changing climate change is essential for the long-term sustainability of agriculture. As mentioned earlier, the countries in temperate and polar locations may benefit as additional temperature may be good for their agricultural sector but the ones in the tropical and sub-tropical may suffer.

\section{Climate Change and Agriculture in Nepal}

It is quite amazing that within the span of $200 \mathrm{~km}$ from north to south, the climate of Nepal varies from artic to tropical. Nepal also enjoys the four normal seasons: spring, summer, autumn and winter. The annual mean temperature is about $15^{\circ} \mathrm{C}$ and increases from the north to south with exceptions in valleys. The annual mean precipitation is around $1800 \mathrm{~mm}$ in Nepal but because of greatly diverse topography it ranges from more than $5000 \mathrm{~mm}$ in the south to less than $250 \mathrm{~mm}$ in the north. Spatial distribution of rainfall is also of great concern regarding the occurrence of floods, landslides and other extreme events. Most floods occur during the monsoon season when heavy precipitation coincides with snowmelt in the mountains.

The agriculture sector provides employment to around $65 \%$ of the population but since it is mostly subsistence it contributes only about $38 \%$ to the total Gross Domestic Product. Because the Nepalese economy depends heavily on tourism and agriculture, it is very sensitive to climate variability. Hydro-power is the primary source of electricity and has a huge potential for growth but it is susceptible to glacier lake outbursts due to climate change. Nepal would be affected by the climate change impacts at several fronts: hydropower, irrigation, domestic water uses and disasters. 
Around $40 \%$ of the land resource in Nepal is covered by the forests. Agriculture stands second in terms of use of land as it covers around $27 \%$. Because of the growing demands of the population, not so satisfactory land productivity and limited opportunities in non-farm activities, expansion of agricultural land continues with each passing year. The demand for water for irrigation in the agricultural sector has increased tremendously. The irrigated area expanded from 0.439 million hectares in 1984 to 0.88 million ha in 1998.

According to studies done by the Department of Hydrology and Meteorology, the average temperature in Nepal is increasing at the rate of approximately 0.06 degrees Celsius per year. Nevertheless, the temperature in the Himalayas is increasing at a faster rate and this can have serious impacts on the country's glacial lakes. Although definitive trends in aggregate precipitation have not been determined, there are evidences of more intense precipitation events. Glacial lake outbursts could also destroy hydro-projects and cause floods and landslides. Contradictorily, glacier retreats have also been recorded which would lead to contracted flow of water during drier seasons. Therefore, because of climate change and the rising temperatures, Nepal could face drier phases during dry seasons with wetter monsoon (as much as three times the current level of rainfall) with chances of flooding and landslides during rainy seasons with subsequent impacts on agriculture and livelihoods(Alan M, Regmi B.R., 2005).

About $80 \%$ of water in Nepal is used for irrigation. Vulnerability of rice yield showed that at $4{ }^{\circ} \mathrm{C}$ increase in temperature and $20 \%$ increase in precipitation, there could be yield increase only from 0.09 to $5.5 \%$ and beyond that the yield would continue to decline. With maize, it was found that increased temperature would lead to decreased yield. However, the result was mixed in case of wheat. The changes in temperature and precipitation will also alter the hydrological cycle and the water resources. As mentioned earlier, since Nepalese agricultural sector is highly dependent on the weather, climate change has serious consequences. Glacier retreats combined with higher temperatures, increased evapo-transpiration, lower soil moisture levels and decreased winter precipitation may bring about droughts in Nepal from November to April. Such draughts or very low rainfall levels at critical points in the development phases of winter and spring crops can dramatically reduce crop yields and livestock numbers and productivity. Reduced precipitation and moisture availability could also hamper the grasslands, fodder and forage production and productivity and this accompanied by heat stress to livestock would mean decreased livestock production and productivity. Even though such fluctuations can be countered by investments in irrigation or by greater food imports, Nepal, a poor country, can probably take those measures effectively. Then on the other hand, monsoon precipitation coinciding with snowmelt in the mountains could lead to floods during rainy seasons damaging not only agriculture and livestock but also the livelihoods of many people. All this would culminate to decreased crop yield and lower livestock productivity which if uncompensated by rising imports may threaten even the food security concerns (Alan M, Regmi B.R., 2005).

The narrative above highlights the implications that the climate change can have on Nepalese agriculture and even on food security. Unlike developed countries where considerable amounts of researches have been conducted and therefore better preparatory course of actions have already been designed, due to Nepal's low level of development and complex topography, it is even more vulnerable to climate change. Nonetheless, certain actions can be taken to mitigate or to adapt to the climatic changes. 


\section{Technology and Policy Options}

A few emergency management items such as construction of emergency shelters and provision of housing for disaster-affected families have been proposed in the tenth plan but given the enormity of climate change, policies that help slow down the climate change and those that aid to adapt are also required (Alan M, Regmi B.R., 2005). Referring to accounts given previously in this paper, actions need to be taken to reduce the rates and quantity of the Greenhouse Gases released by agricultural related activities. Policies can be taken to impose environmental taxes on nitrogen fertilizers, promote better timing of fertilizer and manure applications, development of rice cultivars emitting less methane, better feed quality for livestock, improved livestock waste management and expansion of agro-forestry. On adaptive side, measures such as breeding of greater tolerance of crops, vegetables, livestock and fish to higher temperatures, development of low-cost water conservation technologies, development of early warning and drought and flood forecasting systems, preparedness plans for relief and rehabilitation, development and implementation of land use systems that stabilize slopes and reduce the risks of soil erosion and landslides, and construction of livestock shelters and food stores can be taken to alleviate the effects of extreme conditions affecting agriculture and livelihoods (IISD \& IES, 1997).

\section{Conclusion and Recommendation}

Because the human activities have been merged with the natural phenomenon of climate change, its rapid change than in the past is unstoppable. However, serious preparedness and actions taken from presently can hopefully impede that process and slowly but surely adapt to the rapidly changing climate. For that end, and remaining within the scope of agriculture, actions should be taken to reduce agriculture's role as a driving force for climate change through the reduction of the Greenhouse Gases emissions and also take measures to mitigate and adapt to climate change. Institutional actions are also needed to raise national preparedness to enable vulnerable low-income groups to remain food secured and the aim of the agricultural development should not only be to enhance its productivity and production but also focus should be given to agricultural diversity and resilience.

\section{REFERENCES}

1. The Independent, May 9, 2007, page 1, column 2.

2. Alan M, Regmi B.R., 2005, Adverse Impacts of Climate Change on Development of Nepal: Integrating Adaptation into Policies and Activities, Capacity Strengthening of Least Developed Countries for Adaptation to Climate Change (CLACC).

3. International Institute for Sustainable Development (IISD) and the Institute for Environmental Studies (IES), March 1997, Agriculture and Climate Change: A Prairie Perspective, University of Toronto.

4. Natural Resources Conservation Service (NRCS), October 1995, Agriculture and Climate Change, RCA Issue Brief \# 3, United States Department of Agriculture. 